\title{
"FALTA UM JORGE": A SAÚDE NA POLÍTICA MUNICIPAL PARA MIGRANTES DE SÃO PAULO (SP)
}

Isadora Steffens

Mestranda do Instituto de Relações Internacionais (IRI-USP); integrante do Grupo de Pesquisa sobre Políticas Locais para Migrantes e do Projeto Cosmópolis. São Paulo, SP. Brasil.

Email < isadorasilveirasteffens@gmail.com>

Jameson Martins

Mestrando do Instituto de Relações Internacionais da Universidade de São Paulo (IRI-USP);

integrante do Grupo de Pesquisas sobre Políticas Locais para Migrantes, vinculado ao Projeto de Extensão Cosmópolis (IRI-USP). São Paulo, SP. Brasil.

Email<javims.ri@gmail.com>

http://dx.doi.org/10.1590/ 0102-6445275-299/98

O Estado de São Paulo afirmou-se historicamente como polo nacional de recepção de fluxos migratórios (Baeninger, 2005). Nos anos 1990, é na metrópole de São Paulo que a migração internacional dos trabalhadores globais se concentra (Patarra e Baeninger, 2006). O recente aumento da visibilidade do tema migração na sociedade brasileira deve-se, entre outros fatores, à concentração de comunidades de migrantes na cidade de São Paulo (Reis, 2011). A Prefeitura de São Paulo estima que residam no município atualmente pouco mais de 370 mil imigrantes ${ }^{1}$, cuja presença impacta a administração local, em especial no que se refere à oferta de serviços públicos aos contingentes migrantes socialmente mais vulneráveis.

A despeito do volume e da persistência dos fluxos migratórios nas últimas décadas, pode-se afirmar que são muito recentes as iniciativas do poder público municipal - $\mathrm{e}$

1 Dados da Coordenação de Políticas para Migrantes (CPMig) da Prefeitura de São Paulo, baseados no Sistema Nacional de Cadastramento de Registro de Estrangeiros, da Polícia Federal. O número de imigrantes não regularizados permanece incerto diante da dificuldade em coletar dados a respeito desse grupo. 
mesmo inéditas, se levarmos em conta o contexto brasileiro - de conceber políticas públicas locais eficientes para essa população. As políticas migratórias forjam-se tradicionalmente no seio dos Estados nacionais, que definem regras de acesso e permanência em seu território. No Brasil, por exemplo, ainda vige o Estatuto do Estrangeiro (Lei ${ }^{\circ}$ 6.815, de 19 de agosto de 1980), que aborda o fenômeno migratório sob o prisma da segurança nacional, em detrimento dos direitos dos migrantes ${ }^{2}$.

A moldura jurídica derivada da Constituição Federal de 1988, no entanto, alterou substancialmente a extensão dos direitos assegurados pelo Estado brasileiro aos nacionais e não nacionais. Como consequência, observa-se hoje uma disfunção jurídico-administrativa que posiciona os governos locais na linha de frente das demandas resultantes da chegada e permanência de grupos populacionais importantes. Assim, o reconhecimento de direitos exige dos serviços 276 públicos municipais, por sua proximidade à pessoa humana, uma adaptação à mobilidade humana contemporânea como um fato incontornável.

Nesse sentido, São Paulo corresponde ao que Sassen (2006) definiu como cidade global: um espaço em que os processos transnacionais - entre eles, a migração - concentram-se e assumem formas localizadas, justapondo setores líderes do capital mundial e uma crescente massa de marginalizados e minorias. Como palco de conflitos e contradições, a cidade global cria aberturas para que atores políticos antes invisíveis passem a reivindicar direitos à cidade, representando uma espécie de "zona de fronteira" na luta por direitos (Sassen, 2006, p. 314). Nesse contexto, cresce

\footnotetext{
2 No momento de conclusão deste artigo, tramitava no Congresso Nacional o Projeto de Lei $\mathrm{n}^{\circ}$ 2.516/2015, que instituiria uma nova lei de migração no Brasil e revogaria o Estatuto do Estrangeiro vigente. Para atualização a respeito, acesse: <http://www.camara.gov.br/proposicoesWeb/fichadetramitacao?idProposic $\mathrm{ao}=1594910>$.
} 
a interface entre a mobilidade humana e a saúde global, visto que tanto as políticas migratórias como a sua ausência causam impacto significativo sobre a saúde dos migrantes (Ventura, 2015).

Este artigo se debruça sobre os desafios que representam para o poder público municipal de São Paulo, no âmbito da atenção à saúde, a chegada e a permanência da população migrante. O título do artigo refere-se a um agente comunitário de saúde boliviano chamado Jorge, cujo papel atual e potencial na saúde local será destacado ao longo do texto.

Empregando métodos qualitativos, a pesquisa teve como fontes entrevistas, pesquisa documental e revisão de literatura. As entrevistas de agentes municipais da área da saúde correspondem a dois momentos: o diagnóstico realizado no âmbito do Projeto de Extensão Universitária Cosmópolis ${ }^{3}$, em 2014, e novas entrevistas realizadas em 2016, com os mesmos atores, para atualização dos depoimentos concedidos. Além disso, consultamos a literatura produzida nos últimos anos sobre políticas municipais para migrantes e sobre comunidades de migrantes estabelecidas em São Paulo que abordava temas de saúde.

Em seguida, analisamos, por meio de documentos da prefeitura, as iniciativas da gestão municipal atual nessa seara, a fim de observar seus avanços e limitações. Por fim, apresentamos um balanço da política municipal no campo da saúde e possíveis desdobramentos a partir de suas contingências políticas e econômicas.

3 O Projeto Cosmópolis é um convênio de extensão universitária entre a Coordenação de Políticas para Migrantes (CPMig) e o Instituto de Relações Internacionais da Universidade de São Paulo (IRI-USP), firmado em dezembro de 2013 e renovado recentemente, com o objetivo de subsidiar uma pioneira política municipal para migrantes. Os autores deste artigo fazem parte do Projeto Cosmópolis desde setembro de 2015 . 


\section{Atendimento em saúde à população migrante: diagnóstico preliminar}

O acesso universal e igualitário aos serviços de saúde é garantido pelo artigo 196 da Constituição Federal de 1988, como elemento fundamental do direito à saúde ${ }^{4}$. No Sistema Único de Saúde (SUS), o princípio da universalidade supõe que todos os brasileiros tenham acesso igualitário aos serviços de saúde e respectivas ações, sem qualquer barreira de natureza legal, econômica, física ou cultural (Paim e Silva, 2010), garantindo assim os direitos dos migrantes independentemente de documentação e status migratório. No entanto, na prática, questões como falta de informação sobre o funcionamento do sistema, diferenças linguísticas e culturais, discriminação e condições de trabalho e moradia podem dificultar a efetivação de tal direito. Nosso objetivo, aqui, é apresentar um diagnóstico preliminar do atendimento à saúde de migrantes pela rede pública da cidade de São Paulo, cotejando as entrevistas realizadas

278 com outros estudos recentes sobre o atendimento a migrantes na área da saúde, de maneira a verificar em que pontos esses estudos convergem ou divergem.

Foram entrevistados, entre 2014 e 2016, agentes municipais que mantêm contato com migrantes no âmbito da saúde: Rosa ${ }^{5}$, à época funcionária administrativa da Supervisão Técnica de Saúde (STS) na Sé e que atualmente trabalha no atendimento direto em um hospital; e Ana, à época dentista na Unidade Básica de Saúde (UBS) Casa Verde e hoje atuante na UBS Integral Jardim Edite.

Os migrantes chegam às unidades de saúde espontaneamente, encaminhados por agentes comunitários (no caso, do

\footnotetext{
4 CF 1988: Art. 196. "A saúde é direito de todos e dever do Estado, garantido mediante políticas sociais e econômicas que visem à redução do risco de doença e de outros agravos e ao acesso universal e igualitário às ações e serviços para sua promoção, proteção e recuperação". Disponível em: <http:/ conselho.saude.gov. br/web_sus20anos/20anossus/legislacao/constituicaofederal.pdf $>$. Acesso em: 25 jun. 2006.

${ }_{5}$ Utilizamos nomes fictícios para preservar a identidade das entrevistadas.
} 
Programa Saúde da Família - PSF) ou por organizações da sociedade civil, como a Missão Paz, o Centro de Apoio e Pastoral do Migrante (CAMI), e o Centro de Direitos Humanos e Cidadania do Migrante (CDHIC). Sobre esse aspecto, Rosa destaca a importância da grande rede de organizações da sociedade civil existente na cidade: "A gente também concluiu que a sociedade civil está muito mais avançada no cuidado com o imigrante do que o poder público que está muito precário nos cuidados com o imigrante em todas as áreas [...]" (Rosa, 2014).

A importância do acesso à saúde pode ir além de seus resultados previsíveis (Xavier, 2010), pois, em muitos casos, o Cartão Nacional de Saúde constitui a primeira e por vezes a única identificação dos migrantes, além de um meio de inserção na cidade e de gozo dos respectivos direitos. Em função do princípio da universalidade do SUS, estrangeiros podem se cadastrar no sistema mesmo sem possuir documentos brasileiros de identificação. O Cartão poderia permitir ainda a obtenção de dados quantitativos sobre o acesso dos imigrantes aos serviços de saúde, embora haja, como veremos adiante, escassez de informação nesse sentido - em fevereiro de 2015, havia apenas 39.474 imigrantes cadastrados no sistema (Aguiar, Neves e Lira, 2015, p. 26).

As entrevistadas salientaram diversos desafios: idioma, discriminação, despreparo de agentes de saúde, falta de informação sobre o SUS para os migrantes, falta de atenção entre os altos cargos da saúde para o tema, além de escassez de dados. O idioma é apontado como principal empecilho no acesso de imigrantes a serviços de saúde e a serviços públicos em geral em diversos estudos (Aguiar, Neves e Lira, 2015; Ipea, 2015; Waldman, 2011). Rosa destacou a dificuldade em encontrar funcionários que falem uma segunda língua, e casos especialmente difíceis, como o dos bolivianos provenientes de áreas rurais, cuja língua materna é quéchua ou aymara e não espanhol, ou o grande número de gestantes 
chinesas na UBS Sé - 170 das 300 gestantes atendidas são de origem chinesa - que não falam português (Rosa, 2014). Nesse aspecto, Ana relatou, na ocasião da segunda entrevista, que observou avanços na atuação municipal, principalmente em relação à comunicação em outros idiomas, como o início de um processo que deve avançar abordando questões como a interculturalidade no atendimento (Ana, 2016).

É evidente que a diversidade de origens dos migrantes que chegam à cidade impõe de pronto o desafio de oferecer um atendimento de saúde qualificado sem margens a mal-entendidos, o que pode comprometer os tratamentos (OIM, OMS, ACNUDH, 2013; Aguiar e Mota, 2014). A fim de debelar a barreira idiomática, medidas como a criação de material educativo na língua de origem dos pacientes já se mostrou uma estratégia eficiente para fomentar sua aproximação e adesão ao serviço, especialmente às campanhas de saúde da família (Calixto et al., 2012). Outro método interessante de 280 inclusão dos migrantes ao atendimento é o recurso aos meios de comunicação criados por sua própria comunidade, como o demonstra a utilização das rádios bolivianas da Zona Central como difusoras de informação sobre saúde.

Nas oficinas é muito comum o rádio ligado o tempo todo, um veículo que orienta com informações de toda ordem, inclusive saúde, alertando para o perigo da tuberculose, e fazem propaganda de unguentos e pomadas para dores na coluna e cãibras, corriqueiras entre eles (Aguiar e Mota, 2014, p. 502).

Diretamente relacionada à questão linguística está a desinformação sobre o SUS. Rosa relata que muito frequentemente os migrantes indocumentados temem acessá-lo por receio de denúncias, ou evitam o atendimento por não entenderem que se trata de um direito: "elas não sabem. Elas pensam que é privado, que é pago, como era no país de origem delas" (Rosa, 2014). 
Quanto a esse aspecto, uma pesquisa realizada pelo Instituto de Pesquisa Econômica Aplicada (Ipea) em âmbito nacional revelou que 69,6\% da amostra de organizações formadas pelos próprios imigrantes afirmaram não ter encontrado problemas no acesso aos serviços públicos de saúde; no entanto, para 62,5\% dos entrevistados pertencentes a essas organizações, existiram, sim, problemas (Ipea, 2015, p. 126). Além disso, quando questionados sobre as principais dificuldades que os imigrantes enfrentam no Brasil, 18,2\% das instituições públicas e $8,3 \%$ da sociedade civil apontaram a saúde. Entretanto, essa questão não apareceu como dificuldade significativa nas entrevistas com os próprios imigrantes (Ipea, 2015, p. 127).

Tais resultados poderiam ser reflexo da comparação que os imigrantes fazem entre o SUS - que, apesar de suas deficiências, é um sistema universal e gratuito que legalmente não impõe limitações ao acesso de imigrantes, independentemente de seu status - e os sistemas de saúde de seus países de origem, que nem sempre consagram princípios como a universalidade e a gratuidade dos serviços. A ausência de informação dos migrantes sobre seus próprios direitos em relação ao SUS poderia também explicar esse resultado.

Ademais, as entrevistadas pelo projeto Cosmópolis também se referiram à falta de uma cultura de acolhimento aos imigrantes, traduzida em despreparo e xenofobia por parte de agentes de saúde. Os casos por elas relatados mostraram que o desconhecimento da cultura do paciente pode gerar situações como um diagnóstico equivocado ou uma percepção, por parte dos pacientes, de desrespeito ou insuficiência do atendimento.

Ana, que é migrante natural de La Paz (Bolívia), contou que, ao voltar a São Paulo, em 2008, após um período de estudos, surpreendeu-se com o crescimento de estereótipos negativos sobre migrantes na mídia, especialmente em relação aos bolivianos (Ana, 2014). No âmbito da saúde, ela 
considera que os principais problemas ocorrem na atenção secundária, pois a atenção dedicada ao paciente é menor e não se estabelecem vínculos, o que gera um tratamento inadequado às demandas e às necessidades dos imigrantes. Ana denuncia a xenofobia do nível secundário do atendimento à saúde a partir de uma experiência pessoal:

Um caso muito emblemático aconteceu quando fui levar minha irmã ao Hospital Tatuapé. Pude perceber a condição de abandono total que se encontra a atenção secundária com relação ao imigrante. Foi uma terrível experiência antropológica. É notório que priorizam os brasileiros (Ana, 2014).

Dois anos depois da primeira entrevista, Ana afirmou ter percebido melhoras em relação à xenofobia na área da saúde, em parte devido à abordagem humanitária do refú282 gio, que ganhou visibilidade com a chegada da população síria (Ana, 2016). Rosa acredita que imagens negativas dos migrantes constatadas em meio ao funcionalismo público ocorrem não raro por falta de preparo e desconhecimento da cultura e dos direitos dessa população. Ela também presenciou xenofobia por parte de agentes de saúde.

O despreparo de alguns gerentes para lidar com essa realidade, o desconhecimento da realidade dos imigrantes, eventualmente alguma xenofobia: [reproduz a fala dos agentes] "por que a gente tem que atender os estrangeiros se a gente mal consegue dar conta da nossa própria população brasileira?” (Rosa, 2014).

Esses desafios agem em conjunto, provocando um distanciamento entre os imigrantes e os serviços de saúde. Como se sabe, é no ambiente da atenção básica, de responsabilidade das UBS, que se dá o contato mais próximo com 
a população em geral, inclusive os imigrantes. Portanto, haveria nesse âmbito maior espaço para a preparação dos agentes de saúde para atendimento aos migrantes, tanto em relação ao idioma quanto às culturas. Rosa, ao tratar dos determinantes sociais da saúde, afirma que um funcionário de UBS "precisa entender de sociologia, de economia, de política, de filosofia, de psicologia”, de modo a oferecer um tratamento adequado ao perfil do paciente (Rosa, 2014).

Ana aponta que a UBS deve se adequar à realidade local do território ao qual está restrita, porém não existe um tratamento específico previsto para os imigrantes, e há dificuldade em garantir a adesão das pessoas ao acompanhamento: na UBS Casa Verde, onde trabalhava, apenas $30 \%$ dos indivíduos visados comparece à unidade. Segundo ela, a maioria dos imigrantes recorre à UBS apenas quando está doente, dificultando ações de prevenção (Ana, 2014).

Algumas iniciativas para enfrentar esses desafios realizaram-se no contexto da Estratégia Saúde da Família (ESF), criada para facilitar a aproximação entre os serviços de saúde e a população, que instaurou a contratação de agentes comunitários em saúde e sua visita às moradias das pessoas. Ana destaca o programa de triagem externa, pela qual agentes se deslocam às oficinas de costura onde trabalham os imigrantes, de modo a descentralizar a primeira etapa do atendimento. Rosa, por sua vez, relata a experiência na UBS Bom Retiro, unidade que integra a STS Sé. O distrito de Bom Retiro é o local com maior presença de migrantes em relação à população geral na cidade de São Paulo, sendo 15,98\% de seus habitantes migrantes. Segundo Rosa, havia inicialmente "uma enorme resistência por parte dos bolivianos de abrirem as suas casas, ou das suas oficinas de costura", uma vez que "muitos deles estavam sendo violentamente explorados, então eles tinham medo de abrir a porta para a saúde entrar". A seguir, ela faz referência ao migrante que dá nome ao presente artigo: 
Foi contratado um agente comunitário de saúde, o seu Jorge, que é um boliviano. Então ele fez uma parceria com uma rádio local e começou a falar na rádio sobre o que era a UBS Bom Retiro, o que se fazia, dava [sic] vacina nas crianças, que cuidava do pré-natal das mulheres grávidas [...]. Com o trabalho do seu Jorge as portas começaram a ser abertas e hoje na UBS Bom Retiro, por exemplo, é quase inexistente um lugar em que as pessoas não sejam atendidas pela saúde pública, porque fizemos essa parceria de ter um trabalhador boliviano (Rosa, 2014).

A lógica subjacente à contratação do agente comunitário de saúde (ACS) imigrante obedece aos mesmos princípios determinados pelo Ministério da Saúde sobre as atribuições desse cargo, isto é, "orientar as famílias para a utilização adequada dos serviços de saúde" e "informar os demais membros da equipe de saúde acerca da dinâmica social da comu284 nidade, suas disponibilidades e necessidades" (Brasil, 1997). Nesse sentido, a pertença do agente ao mesmo universo cultural dos usuários lhe faz compreender melhor as carências e os conflitos internos àquela comunidade (Nunes et al. 2002).

Considerando a necessidade das equipes de saúde de levar em conta os determinantes sociais da doença (Aguiar e Mota, 2014), o recurso ao ACS imigrante contribui para minimizar a escassez de dados a respeito do acesso dos imigrantes aos serviços públicos de saúde. Esse efeito evidenciou-se no caso dos bolivianos, cujos problemas de saúde mais recorrentes - lesões musculares e tuberculose - se encontram intimamente relacionados à exaustiva rotina de trabalho nas oficinas de costura, onde residem e trabalham simultaneamente em boa parte dos casos (Goldberg e Silveira, 2013; Aguiar e Mota, 2014).

Porém, diversos grupos nacionais na cidade não são identificáveis pelo sistema devido à ausência de pontes e procedimentos institucionais de registro e acompanha- 
mento nos cadastros oficiais de saúde. De acordo com a Secretaria Municipal da Saúde (SMS), há dificuldades em contratar agentes de nacionalidade sul-coreana ou chinesa, e os dados no Sistema de Informação da Atenção Básica (SIAB) sobre a nacionalidade dos agentes e suas respectivas áreas de atuação são escassos (Aguiar, Neves e Lira, 2015). Rosa, ao comentar o caso das 170 grávidas chinesas na UBS Sé, afirmou que ali faltaria "um Jorge" (Rosa, 2014). Para superar tantos desafios, a contratação de agentes migrantes seria, portanto, altamente recomendável.

Ana reconhece, no entanto, que de "três anos pra cá foi bem nítido o esforço que se teve em pautar a questão do imigrante dentro da atenção básica, principalmente”, por iniciativa dos próprios funcionários que formavam grupos de trabalho, mas também por iniciativas oficiais do município em capacitação e sensibilização de pessoal (Ana, 2016). Essa visão é confirmada pela experiência de Rosa, que atualmente trabalha em um hospital. Segundo ela, embora de maneira incipiente e penosa, uma nova equipe tem trazido profissionais especializados no tema para conversar com os funcionários do local (Rosa, 2016).

No que concerne ao planejamento, Rosa mencionou a desatenção dos altos cargos da coordenação da saúde para a realidade dos migrantes e sobre a falta de verbas dedicadas à questão. Ela destaca ainda a carência de dados e a importância de incluir a nacionalidade nos formulários de atendimento. À época da primeira entrevista, se realizava uma experiência local de conscientização com as equipes das trinta unidades de saúde que compõem a STS Sé. Contudo, quando da segunda entrevista, nem Rosa nem o supervisor que desenvolveu a experiência trabalhavam no local, e a iniciativa foi interrompida. Não obstante, na avaliação da entrevistada, o projeto teria gerado alguns frutos: "Eu acho que sim, que algumas pessoas foram tocadas e mudaram, ampliaram o horizonte" (Rosa, 2016). 
A respeito da carência de dados, um boletim emitido pela SMS reconhece a séria dificuldade de obter dados sobre o acesso de imigrantes, sobretudo a serviços de saúde da atenção básica - em casos de procedimentos de alta complexidade e internações hospitalares, a nacionalidade é mais bem notificada - devido à ausência de um registro sistemático de dados sobre a nacionalidade nos sistemas de informação da saúde pública. Mais de $70 \%$ dos procedimentos realizados entre 2013 e 2014 no Sistema de Informação Ambulatorial (SIA), por exemplo, não incluíam informação sobre nacionalidade (Aguiar, Neves e Lira, 2015). Ainda sobre questões cadastrais, Ana indicou que as opções de raça - negro, indígena, pardo, branco e amarelo - podem ser inadequadas para a realidade dos imigrantes, pois alguns bolivianos, por exemplo, não se identificam como indígenas (Ana, 2014).

Verificamos que nossas entrevistas corroboram as 286 conclusões de trabalhos acadêmicos precedentes sobre a relação entre os serviços públicos de saúde e as migrações em São Paulo. Embora proporção considerável dos estudos citados tenha como objeto a população boliviana de menor renda, concentrada na região central da capital - o que poderia ser tomado como uma lacuna da produção acadêmica nesse campo -, tais estudos indicam a recorrência de dificuldades semelhantes àquelas elencadas nas entrevistas, como o déficit de comunicação e informação para os imigrantes, o despreparo dos agentes públicos e a gestão ineficiente de dados.

No plano internacional, de acordo com a Organização Mundial de Saúde (OMS), identificam-se adversidades semelhantes na efetividade do direito à saúde das populações migrantes em diversas sociedades receptoras de fluxos migratórios. Os obstáculos linguísticos e culturais, as condições de trabalho degradantes às quais esses grupos estão frequentemente mais expostos, além da ausência de pro- 
fissionais de saúde "culturalmente competentes", isto é, que reconhecem e incorporam "habilidades interpessoais no trato de pacientes de diferentes bases culturais" (OIM, OMS, ACNUDH, 2013) apresentam-se como desafios à garantia do direito humano à saúde em face da mobilidade humana contemporânea.

\section{As iniciativas da atual gestão do Município de São Paulo}

Diante dos desafios apontados na seção anterior, passamos a analisar as iniciativas da atual gestão do Município de São Paulo no que diz respeito à saúde da população imigrante. Para tal, examinaremos o Plano Municipal de Saúde 2014-2017, a Programação Anual de Saúde 2016 e a Política Municipal para a População Imigrante - os dois últimos ainda em construção.

A Política Municipal para a População Imigrante é um documento geral que busca contemplar as diversas áreas do serviço público que tratam da questão migratória, elaborado no âmbito da Coordenação de Políticas para Migrantes (CPMig), enquanto os outros dois documentos foram produzidos pela Secretaria Municipal de Saúde (SMS). Também com base em documentos da SMS, mencionaremos a elaboração de uma Política de Saúde para a população imigrante, embora não tenhamos obtido acesso a esse documento.

No Plano Municipal de Saúde 2014-2017, documento que delimita as metas suprarregionais para o período, por Coordenadoria Regional de Saúde (CRS) e por subprefeitura, existem quatorze referências à temática da imigração. Em nove delas, o termo "imigrantes" foi listado ao lado de outras populações - como idosos, LGBTT, moradores de rua, entre outros - em medidas não voltadas exclusivamente para a questão da migração, mas para as especificidades de grupos sociais em geral (Prefeitura de São Paulo, 2014).

As demais menções referem-se a metas específicas para a população migrante. No âmbito suprarregional, apenas 
uma meta foi apontada: a realização anual de um curso de atualização em "saúde da população do imigrante" para assistentes de gestão de políticas públicas. Na esfera das CRS, a CRS Centro apresentou como meta a implementação de Núcleos de Referência de Acolhimento em Saúde ao Imigrante em quatro UBS da região, enquanto a CRS Sudeste apresentou a implementação de uma pesquisa de satisfação para avaliar a assistência aos migrantes da região, de maneira a fornecer subsídios para "sensibilizar e capacitar a equipe para acolher o imigrante e investir em comunicação visual e linguística" (Prefeitura de São Paulo, 2014, p. 153). Já no que concerne às subprefeituras, Vila Maria/ Vila Guilherme afirmou como meta "manter uma sistemática para captação e inclusão da população de imigrantes no território" (p. 252). Por fim, a subprefeitura da Mooca definiu como objetivo a melhora na comunicação visual e linguística para ampliar o acesso dos migrantes, com sensi288 bilização e capacitação das equipes (p. 319).

Constatamos, portanto, diversos aspectos salientados nas entrevistas, como comunicação visual e linguística, sensibilização, capacitação e coleta de dados. No entanto, são medidas tímidas e pontuais, uma vez que o documento não demonstra um conjunto de metas que efetivamente estabeleçam uma política compreensiva para as especificidades dessa população. Ainda assim, comparado ao Plano Municipal de Saúde 2010-2013, que menciona brevemente os imigrantes em apenas duas metas não direcionadas especificamente a essa população, o atual Plano representa um avanço significativo.

A Programação Anual de Saúde 2016, da Prefeitura de São Paulo, por sua vez, apresentou uma novidade importante ao incluir, pela primeira vez, uma área temática dedicada à Saúde do Imigrante e Refugiado. As metas apresentadas consistem, entre outros, na contratação e capacitação de profissionais - e/ou os próprios migrantes - para facilitar 
a interlocução com essa população, geração e análise de dados, comunicação em diferentes línguas e culturas, criação de uma rede de apoio, promoção de fóruns de trocas de experiência e captação de recursos (Prefeitura de São Paulo, 2016, p. 27). A criação de uma parte do documento dedicada exclusivamente a essa temática abre um precedente para que as próximas programações de saúde sigam reconhecendo os imigrantes e refugiados como uma população com demandas específicas, exigindo a formulação de metas que atendam às suas especificidades.

No que diz respeito à coleta de dados sobre o acesso de imigrantes e refugiados ao sistema de saúde, a SMS publicou recentemente o já mencionado boletim que reúne informações do sistema SUS, das Coordenadorias Regionais de Saúde (CRS) e das Supervisões Técnicas de Saúde (STS), bem como pesquisa realizada por formulário eletrônico pelo Grupo de Trabalho Imigrantes e Refugiados junto aos estabelecimentos da rede municipal de saúde (Aguiar, Neves e Lira, 2015). A escassez de dados, sobretudo na atenção básica, resultado da não notificação da nacionalidade nos formulários de atendimento, é reconhecida pelo próprio boletim. A principal contribuição do documento é a compilação e sistematização dos dados já existentes até então, de maneira a apontar lacunas e auxiliar o trabalho de construção e implementação da política.

Finalmente, teve início em 2014 o processo de elaboração de uma política de saúde para imigrantes no âmbito municipal, com a formação de um grupo de estudos para conceber uma proposta. A política teria sido aprovada no ano seguinte e se criaria um grupo de trabalho para operacionalizá-la, em conjunto com a Organização Pan-Americana da Saúde/Organização Mundial da Saúde (OPAS/OMS) (Aguiar, Neves e Lira, 2015). De fato, no dia 28 de janeiro de 2016, a parceria se formalizou com a assinatura de um termo de cooperação entre a OPAS/OMS e a Prefeitura de 
São Paulo nas áreas de saúde da população de imigrantes e refugiados, atenção básica e saúde mental (OPAS, 2016).

No entanto, a política ainda não foi divulgada publicamente e, de acordo com a Ata da $198^{\mathrm{a}}$ Reunião Plenária do Conselho Municipal de Saúde, de 13 de agosto de 2015, a deliberação sobre sua aprovação foi adiada por falta de quórum (Prefeitura de São Paulo, 2015). Segundo o documento, as propostas elaboradas a partir de rodas de conversa realizadas com profissionais de saúde, imigrantes e refugiados, organizações da sociedade civil e Secretaria Municipal de Direitos Humanos e Cidadania (SMDHC) estariam organizadas em quatro eixos: organização dos processos de trabalho interno, comunicação, financiamento e inclusão da temática de migração nas políticas públicas. Até a conclusão do presente texto, não havia sido possível obter informações sobre o atual estágio dessa política.

Já a Política Municipal para a População Imigrante 290 constituiu-se no âmbito da Coordenação de Políticas para Migrantes (CPMig), com a participação de diversas secretarias e atores da sociedade civil. A cidade de São Paulo, tradicional receptora de migrações, não possuía um órgão dedicado especialmente às políticas migratórias até os primeiros meses de 2013, quando foi instaurada a CPMig, iniciativa inédita no país. O objetivo da CPMig é articular as políticas nos diversos níveis e áreas relacionadas à migração na administração municipal. A Coordenação integra a SMDHC e seus valores e princípios são pautados por uma linguagem de direitos, o que indica avanços em relação à legislação nacional vigente:

[...] o reconhecimento da importância dos novos fluxos migratórios para a cidade de São Paulo e dos imigrantes como sujeitos de direitos; a promoção e a garantia de seus direitos fundamentais; a promoção da integração social e cultural mediante o intercâmbio de saberes entre 
as diferentes comunidades no espaço público; a não criminalização daqueles que migram e o respeito ao direito de mobilidade (Prefeitura de São Paulo, s.d.).

Assim, a CPMig representa uma inovação institucional da gestão municipal e demonstra, pelo texto de seus princípios e por sua inserção na SMDHC, uma abordagem à questão migratória calcada nos direitos humanos dos migrantes. Por conseguinte, a política municipal para migrantes que lhe foi atribuída pelo Programa de Metas da Cidade de São Paulo 2013-2016, documento composto de 123 propostas da gestão atual do município, pauta-se pela transversalidade e intersetorialidade no que se refere ao atendimento à população migrante.

Com esse propósito, o Decreto Municipal $\mathrm{n}^{\circ} 56.353$, de 24 de agosto de 2015, instituiu o Comitê Intersetorial da Política Municipal para a População Imigrante (doravante Comitê), órgão temporário composto por representantes da sociedade civil e do Poder Público Municipal ${ }^{6}$, encarregado da elaboração da proposta de política municipal sobre a qual se baseará a implementação das políticas públicas dirigidas a essa população. No momento da redação deste artigo, o texto derivado do Comitê encontrava-se em fase de consulta pública eletrônica, como parte de um processo participativo de construção dessa política.

A Política, na versão apresentada para a consulta, é composta por 23 artigos, que contemplam tanto princípios e diretrizes gerais como medidas nas áreas de saúde, assistência social, moradia, trabalho, educação, esporte, transporte e cultura. O artigo 12 é exclusivamente dedicado à área da saúde, além de disposições gerais aplicáveis a esse setor.

${ }^{6}$ Os autores deste artigo integraram o Comitê como representantes do Projeto Cosmópolis. 
$\mathrm{O}$ artigo $2^{\circ}$, por exemplo, em seu inciso IV, explicita como princípio da política o "combate à xenofobia, ao racismo, ao preconceito e a quaisquer formas de discriminação". Constam também no artigo $3^{\circ}$ questões como o fornecimento de informação sobre os serviços públicos municipais à população migrante (inciso VI); a produção, sistematização, conservação e divulgação de dados estatísticos (inciso VII); e a realização e divulgação de avaliações periódicas (VIII). Observamos que o artigo 12 referencia o artigo $3^{\circ}$ ao retomar a ideia de acesso à informação para os imigrantes.

Ainda mais auspicioso, o conteúdo do artigo $4^{\circ}$ prevê a possibilidade de contratação de agentes públicos imigrantes (inciso III), inclusive por concursos públicos, além da criação do cargo de "mediador cultural nos equipamentos públicos com maior afluxo de imigrantes" (parágrafo único). No que concerne à atenção básica de saúde, isso pode representar um avanço considerável nas áreas de maior pre292 sença dessa população, cujas lacunas de comunicação com as equipes de saúde se tornaram menos expressivas a partir da contratação de agentes comunitários imigrantes com maior trânsito entre os seus pares.

Como evidenciado nas entrevistas e observado pela literatura (Aguiar e Mota, 2014), a contratação de agentes públicos, em especial os agentes comunitários de saúde, constitui uma ponte valiosa entre o serviço e seus usuários. O "seu Jorge", ACS boliviano da UBS Bom Retiro, modificou positivamente a relação entre a população boliviana do bairro e a equipe de saúde, ao prover informação e dirimir as barreiras provocadas pelas condições de trabalho e residência dos migrantes. Simbolicamente, ele atribuiu à face do serviço de saúde os traços de uma parte importante de seu público.

Outra carência apontada nas entrevistas, qual seja, a qualificação dos agentes públicos, é contemplada pelo artigo $4^{\circ}$, que prevê a formação dos agentes públicos brasileiros em diversas áreas, incluindo orientação sobre os direitos 
dos imigrantes e idiomas, em particular nas áreas da cidade em que se concentram os imigrantes. Tal medida, se levada a cabo de forma efetiva na área da saúde, deve contribuir para o enfrentamento de diversos desafios, tais como a dificuldade com o idioma, as manifestações de xenofobia e a ausência da "cultura de acolhimento" a que se referiram as entrevistadas. Além disso, embora reforce o cuidado com a formação dos agentes públicos nas áreas que mais atendem imigrantes, a orientação da política seria prover, ao sistema como um todo, a capacidade de melhor atender a essa população, independentemente de seu endereço.

Atenta às dificuldades constatadas no atendimento aos migrantes, a redação do artigo 12 propõe algumas medidas visando à adequação dos serviços de saúde à (não tão) nova realidade migratória da cidade. O projeto reconhece como "dever da Secretaria Municipal de Saúde promover o acesso à saúde culturalmente adequado para toda a população imigrante, independentemente de sua situação imigratória e documental". Tal redação reforça o princípio da universalidade do SUS e reafirma o compromisso em não restringir o direito à saúde ao migrante sob qualquer circunstância.

Ao mesmo tempo que reconhece o direito à saúde propriamente, o texto matiza o acesso dos migrantes ao serviço público sem ignorar suas "especificidades culturais e religiosas" e seus "diferentes perfis epidemiológicos". Na esteira do reconhecimento das questões culturais envolvendo a saúde dessa população, destaca-se também a previsão de atender especialmente à "saúde da mulher imigrante, inclusive com promoção do parto humanizado e intercultural”. Aqui o projeto se mune da capacidade de promover uma adaptação importante das práticas obstétricas do sistema de saúde brasileiro, já que são recorrentes as queixas de gestantes migrantes (particularmente bolivianas) em relação ao parto cesariano, comum entre as brasileiras, porém con- 
siderado prejudicial e invasivo ao corpo da mulher (Madi, Cassanti e Silveira, 2009).

Entre outras disposições do projeto, é prevista a realização de campanhas de promoção da saúde "adaptadas em termos linguísticos e culturais" aos imigrantes. Esse tipo de ação já tem ocorrido pontualmente em unidades básicas de saúde com presença importante dessa população, como já foi citado. No entanto, a previsão legal dessas iniciativas pode garantir sua continuidade e aperfeiçoamento, mitigando o déficit comunicacional entre equipes de saúde e potenciais usuários migrantes.

O texto do projeto de lei municipal para os imigrantes, ainda nos estágios finais de sua elaboração e, portanto, sujeito a modificações, não deve se eximir, entretanto, de críticas importantes relacionadas às questões de saúde. Entre elas, destacamos a ausência de uma disposição específica que estimule a contratação de agentes de saúde 294 migrantes, cuja prática ainda recente e pontual demonstrou resultados muito positivos no campo da atenção primária. Embora preveja esse tipo de contratação em todas as áreas dos serviços públicos municipais no artigo $4^{\circ}$ do projeto, reiterar explicitamente essa medida no artigo 12 , referente à saúde, parece-nos fundamental para garantir que de fato se reproduza a experiência bem-sucedida da UBS do Bom Retiro, e padronizar, entre as comunidades de diferentes origens, a atuação dos "Jorges", a fim de superar as barreiras entre o atendimento e os usuários.

Uma crítica mais ampla ao projeto poderia apontar a generalidade do texto em seu conjunto, posto que não apresenta dispositivos minuciosos sobre a implementação das propostas. Porém, trata-se de uma lei municipal de caráter programático, que orienta os diversos serviços de forma transversal entre as secretarias de governo, o que deve instigá-las ao detalhamento de suas próprias medidas referentes à questão migratória e ao incremento da colaboração entre as diversas unidades. 
Sendo o fenômeno migratório reconhecidamente multifacetado no que diz respeito à proteção dos direitos dos migrantes, o objetivo é que o trabalho conjunto das diferentes secretarias, sob a égide dos princípios previstos em lei, traga mais consistência à gestão municipal nessa questão. Por outro lado, a maleabilidade do texto do projeto pode ter efeitos negativos, pois pode permitir interpretações distintas e dificultar a implementação das políticas, a depender da disposição dos agentes do poder público e da orientação do governo municipal vigente. Nesse sentido, o texto prevê, em seu artigo $5^{\circ}$, a instauração de um conselho que possa fiscalizar a implementação da política, de composição paritária entre a administração pública municipal e a sociedade civil; esta última majoritariamente composta por imigrantes.

A existência de tal Conselho pode impulsionar a implementação das diretrizes e princípios nos diversos níveis e áreas dos serviços municipais. Não obstante, a efetividade e o poder decisório que se outorgará ao Conselho permanece incerto. A Política Municipal para a População Imigrante representa, portanto, um importante instrumento para que se implementem melhorias no acesso dos imigrantes aos serviços públicos. Em virtude de seu artigo 23, ela deverá ser levada em conta na formulação dos planejamentos orçamentários municipais. Ainda assim, sua execução depende da disposição dos agentes do serviço público nos mais variados setores e da relevância atribuída ao tema pela gestão municipal que tomará posse em 2017.

$* * *$

À guisa de conclusão, o conjunto das medidas postas em marcha pela Prefeitura de São Paulo nos últimos anos no campo das migrações e, em particular, no tocante à saúde, reconhece abertamente um enfoque de direitos humanos na saúde pública (Ingleby, 2009), já que propugna o 
direito à saúde a todos sem distinção por origem ou status migratório. Caso suas disposições se convertam em lei, tratar-se-á de uma política pioneira no âmbito municipal, que potencialmente inspirará iniciativas semelhantes em locais onde as migrações internacionais se incorporaram ao cotidiano urbano.

É relevante que o processo de formulação dessa política não tenha prescindido da participação dos movimentos sociais, que concentram o conhecimento das questões que envolvem as populações migrantes. Uma vez que estas encontram-se ainda desprovidas de direitos políticos e de representatividade direta nos locais que habitam, a abertura da preparação do projeto de lei a membros da sociedade civil provê mais legitimidade ao processo de construção da política pública e a torna mais porosa às reivindicações de agentes sociais de base.

No que se refere à saúde, as medidas se concentram no 296 nível da atenção básica, o que demonstra uma preocupação com a porta de entrada do sistema de saúde pública. É nele que se concentra a demanda por adaptações do serviço público à presença dos migrantes, em termos linguísticos, culturais e das práticas de atendimento.

Se, por um lado, dada a sua incipiência, a política ainda deve passar por um processo de consolidação, dependente de variáveis políticas futuras, por outro lado já se podem identificar compromissos institucionais como o Plano Anual de 2016 e o Plano Municipal de Saúde, além de iniciativas de base em diversas unidades do sistema público de saúde, que podem representar conquistas irrevogáveis no sentido da salvaguarda dos direitos da população imigrante da cidade. Resta saber se o advento dessa política instaurará o reconhecimento definitivo dos direitos dos migrantes pela administração municipal, independentemente da alternância de poder. 


\section{Isadora Steffens}

é mestranda do Instituto de Relações Internacionais da Universidade de São Paulo (IRI-USP) e integra o Grupo de Pesquisas sobre Políticas Locais para Migrantes e o Projeto Cosmópolis, do IRI-USP.

\section{Jameson Martins}

é mestrando do Instituto de Relações Internacionais da Universidade de São Paulo (IRI-USP) e integra o Grupo de Pesquisas sobre Políticas Locais para Migrantes e o Projeto Cosmópolis, do IRI-USP.

\section{Bibliografia}

AGUIAR, B.; NEVES, H.; LIRA, M. 2015. Alguns aspectos da saúde de imigrantes e refugiados recentes no município de São Paulo. Boletim CEInfo Análise, São Paulo, ano X, n. 13.

AGUIAR, M.; MOTA, A. 2014. O Programa Saúde da Família no bairro do Bom Retiro, SP, Brasil: a comunicação entre bolivianos e trabalhadores de saúde. Interface, v. 18, n. 50, pp. 493-506.

BAENINGER, R. 2005. São Paulo e suas migrações no final do século 20. São Paulo em Perspectiva, v. 19, n. 3, pp. 84-96.

BRASIL. Ministério da Saúde. 1997. Saúde da Família: uma estratégia para a reorientação do modelo assistencial. Disponível em: <http:/ /bvsms.saude. gov.br/bvs/publicacoes/cd09_16.pdf>. Acesso em: 10 mar. 2016.

BRASIL. Presidência da República. Casa Civil. Subchefia para Assuntos Jurídicos. 1980. Lei $\mathrm{n}^{\circ} 6.815$, de 19 de agosto. Define a situação jurídica do estrangeiro no Brasil, cria o Conselho Nacional de Imigração. Disponível em: <http://www.planalto.gov.br/ccivil_03/leis/L6815. htm>. Acesso em: 25 jun. 2016.

CALIXTO et al. 2012. Pró-Saúde: uma resposta para a necessidade de informações de mães imigrantes na região central da cidade de São Paulo. Revista Brasileira de Educação Médica, v. 36, n. 2, pp. 223-27.

GOLDBERG, A.; SILVEIRA, C. 2013. Desigualdad social, condiciones de acceso a la salud pública y procesos de atención en inmigrantes bolivianos de Buenos Aires y São Paulo: una indagación comparativa. Saúde e Sociedade, v. 22, n. 2, pp. 283-97.

IBGE. Censo Demográfico 2010. Disponível em: <http:/ /www.censo2010. ibge.gov.br>. Acesso em: Acesso em: 25 jun. 2016. 
INGLEBY, D. 2009. La santé des migrants et des minorités ethniques en Europe Hommes et migrations, $\mathrm{n}^{\circ} 1282$, pp. 136-50.

IPEA - Instituto de Pesquisa Econômica Aplicada. 2015. Migrantes, apátridas e refugiados: subsidios para o aperfeiçoamento de acesso a serviços, direitos e políticas públicas no Brasil. Brasília: Ipea; Ministério da Justiça. (Série Pensando o Direito, n. 57). Disponível em: <http:/ / pensando.mj.gov.br/wp-content/ uploads/2015/12/PoD_57_Liliana_web3.pdf>. Acesso em: 25 jun. 2016.

MADI, M. C.; CASSANTI, A. C.; SILVEIRA, C. 2009. Estudo das representações sociais sobre gestação em mulheres bolivianas no contexto da atenção básica em saúde na área central da cidade de São Paulo. Saúde e Sociedade, v. 18, supl. 2, pp. 67-71.

NUNES, M. et al. 2002. O agente comunitário de saúde: construção da identidade desse personagem híbrido e polifônico. Cadernos de Saúde Pública, v. 18, n. 6, pp. 1639-46.

OIM, OMS, ACNUDH - Organização Internacional para as Migrações, Organização Mundial de Saúde, Alto Comissariado das Nações Unidas para os Direitos Humanos. 2013. International migration, health and human rights. Geneva: OIM. Disponível em: <http://www.ohchr.org/ Documents/Issues/Migration/WHO_IOM_UNOHCHRPublication. pdf>. Acesso em: 25 jun. 2016.

298 OPAS/OMS - Organização Pan-Americana da Saúde/Organização Mundial da Saúde. 2016. OPAS/OMS firma cooperação com município de São Paulo para fortalecer saúde dos imigrantes e refugiados, atenção básica e saúde mental. Disponível em: <http:/ /www.paho.org/bra/index.php?option=com_con tent\&view=article\&id=4986\&Itemid=821> . Acesso em: 25 jun. 2016.

PAIM, J. S.; SILVA, L. M. V. da. 2010. Universalidade, integralidade, equidade e SUS. BIS, Boletim do Instituto de Saúde, São Paulo, v. 12, n. 2. Disponível em: $<$ http:/ / periodicos.ses.sp.bvs.br/scielo.php?script=sci_arttext\&pid=s151818122010000200002\&lng=pt\&nrm=isso >. Acesso em: 25 jun. 2016.

PATARRA, N.; BAENINGER, R. 2006. Mobilidade espacial da população no Mercosul: metrópoles e fronteiras. Revista Brasileira de Ciências Sociais, v. 21, n. 60, pp. 83-102.

PREFEITURA DE SÃO PAULO. s.d. A coordenação. Saiba mais sobre a CPMig. Disponível em: <http://www.prefeitura.sp.gov.br/cidade/ secretarias/direitos_humanos/migrantes/coordenacao/index. php?p=156223>. Acesso em: 25 jun. 2016.

2014. Plano Municipal de Saúde 2014-2017. 3. ed. São Paulo:

Secretaria Municipal da Saúde, Prefeitura de São Paulo. Disponível em: <http://www.prefeitura.sp.gov.br/cidade/secretarias/upload/saude/ planomunicipaldesaudeterceiraedicao.pdf>. Acesso em: 25 jun. 2016. 
Secretaria Municipal de Saúde. Conselho Municipal de Saúde. 2015. Ata da 198a Reunião Plenária Ordinária, 13 ago. Disponível em: <http://www.prefeitura.sp.gov.br/cidade/secretarias/upload/saude/ ATA198REUNIAOORDINARIADOPLENODOCMS130815\%20.pdf>. Acesso em: 25 jun. 2016.

2016. Programação Anual de Saúde 2016. 2. ed. São Paulo: Secretaria Municipal da Saúde, Prefeitura de São Paulo. Disponível em: <http:/ / www.prefeitura.sp.gov.br/cidade/secretarias/upload/saude/ planoanualdesaude2016.pdf>. Acesso em: 25 jun. 2016.

REIS, R. R. 2011. A política do Brasil para as migrações internacionais. Contexto Internacional, v. 33, n. 1, pp. 47-69.

SASSEN, Saskia. 2006. Territory, authority, rights: from medieval to global assemblages. 2. ed. Princeton/Oxford: Princeton University Press.

VENTURA, D. 2015. Mobilidade humana e saúde global. Revista USP, n. 107 , pp. 55-64.

WALDMAN, T. 2011. Movimentos migratórios sob a perspectiva do direito à saúde: imigrantes bolivianas em São Paulo. Revista de Direito Sanitário, São Paulo, v. 12, n. 1, pp. 90-114.

XAVIER, I. R. 2010. Projeto migratório e espaço: os migrantes bolivianos na Região Metropolitana de São Paulo. Dissertação de mestrado. Campinas: IFCH-Unicamp.

\section{Depoimentos}

ANA. 2016. Depoimento. Entrevistadores: Isadora da Silveira Steffens e Jameson Martins. São Paulo, 13 mar. (15:32 min.).

ROSA. 2016. Depoimento. Entrevistadores: Isadora da Silveira Steffens e Jameson Martins. São Paulo, 8 mar. (38:21 min.).

\section{NOTA:}

Onde aparece (Ana, 2014) ou (Rosa, 2014), as referências correspondem a entrevistas contidas no documento: COSMÓPOLIS. 2015. Diagnóstico do atendimento dos migrantes pelos órgãos da Prefeitura Municipal de São Paulo. Relatório de entrevistas - versão para discussão. São Paulo, janeiro de 2015. [não publicado]. 


\section{"FALTA UM JORGE": A SAÚDE NA POLÍTICA MUNICIPAL PARA MIGRANTES DE SÃO PAULO (SP)}

\section{ISADORA STEFFENS}

\section{JAMESON MARTINS}

Resumo: A metrópole de São Paulo, em sua posição de cidade global, concentra processos transnacionais, entre eles a migração - atualmente, estima-se que residam oficialmente pouco mais de 370 mil imigrantes no município. Nesse contexto, cresce a interface entre a mobilidade humana e a saúde global, visto que tanto as políticas migratórias como a sua ausência causam impacto significativo sobre a saúde dos migrantes. O presente artigo se debruça sobre os desafios que representam, no âmbito municipal de atenção à saúde, a chegada e a permanência da população migrante, bem como sobre as recentes iniciativas do poder público municipal de conceber políticas públicas locais eficientes para essa população. Empregando métodos qualitativos, a pesquisa teve como fontes entrevistas, pesquisa documental e revisão de literatura.

Palavras-chave: Saúde Pública; Saúde Global; Migrações Internacionais; São Paulo; Política Pública Municipal.

\section{"LOOKING FOR JORGE": HEALTHCARE IN THE MUNICIPAL POLICY FOR MIGRANTS IN SÃO PAULO (SP), BRAZIL}

Abstract: The metropolis of São Paulo, from its global city position, concentrates transnational processes, among which migration - at present, it is estimated that over 370 thousand immigrants officially reside in the city. In this context, the interface between human mobility and global health broadens out, since both migration policies and their absence have a meaningful impact on migrants' health. The present paper addresses the challenges the arrival and permanence of the migrant population represent to the healthcare municipal sphere, as well as the recent initiatives from the municipal public authority to 
conceive efficient public policies towards this population. By applying qualitative methodology, the research has had interviews, document search, and literature review as sources.

Keywords: Public Health; Global Health; International Migrations; São Paulo; Municipal Public Policy.

Recebido em: 16/3/2016 Aprovado em: 17/6/2016 